\title{
Doctor of Optometry
}

National Cancer Institute

\section{Source}

National Cancer Institute. Doctor of Optometry. NCI Thesaurus. Code C39384.

The Doctor of Optometry degree is the first-professional, postgraduate degree awarded to the graduates who have completed a specialized four year post-baccalaureate professional program in order to become independent health care providers who examine, diagnose, treat, and manage disorders of the visual systems and diseases of the eye and associated structures. 